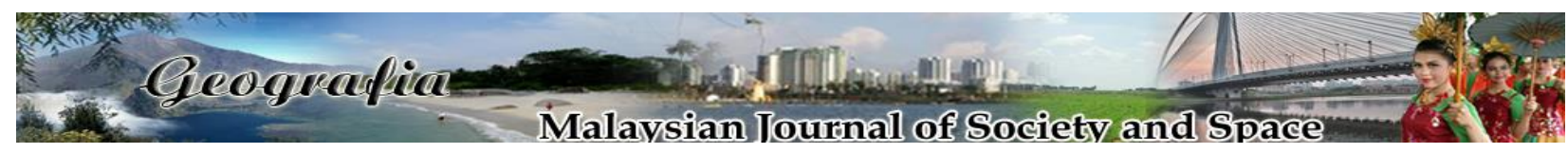

\title{
The analysis of Higher-Order Thinking skills in English reading comprehension tests in Malaysia
}

\author{
Randip Kaur Valdev Singh ${ }^{1}$, Azianura Hani Shaari ${ }^{2}$ \\ ${ }^{1}$ Faculty of Social Sciences and Humanities, Universiti Kebangsaan Malaysia \\ ${ }^{2}$ English Language Studies Programme, Center for Literacy and Sociocultural Transformation \\ Faculty of Social Sciences and Humanities, Universiti Kebangsaan Malaysia \\ Correspondence: Azianura Hani Shaari (email: azianura@ukm.edu.my)
}

Received: 18 December 2018; Accepted: 12 February 2019; Published: 22 February 2019

\begin{abstract}
The current English language education in Malaysia has integrated the Higher-Order Thinking Skills (HOTS) as part of its testing and evaluation system, which aims to enhance students' cognitive skills and abilities in learning. Having a higher-order thinking ability at the earliest stage of formal education (primary and elementary levels) is essential in order to meet the growing demand for highly intelligent and professional workers in the future. The present study aims to identify the use of HOTS items in selected English reading comprehension examinations for Standard 6 students in Malaysia. 80 reading comprehension items were selected from various final examination papers distributed in eight different states in the country. Data were quantitatively analysed using content analysis based on the levels of cognitive listed in Bloom's Taxonomy. Apart from that, the data were also analysed based on a series of professional evaluations made by four content experts in the country. The findings indicate that most reading comprehension questions in the English examination papers need further revisions in order to achieve the standard of HOTS that have become part of the new curriculum and national education policy. Based on the findings, some practical suggestions have also been developed to further enhance the use of HOTS in English teaching and learning practices in Malaysia.
\end{abstract}

Keywords: Bloom's Taxonomy, content analysis, English language assessment, Higher-Order Thinking skills, national education policy, reading comprehension test

\section{Introduction}

The Ministry of Education is implementing a new education system that is capable of producing future Malaysians who are competitive, highly intelligent and independent. In order to compete with others countries, Malaysian education system must shape and produce future generations that are knowledgeable and able to think critically and creatively. The new English language 
curriculum and assessment system in the country has integrated the higher-order thinking skills (HOTS) that is aimed to enhance the cognitive aspect of students in order to become creative, critical and reflective thinkers.

According to the current Malaysian English language assessment in the Ujian Penilaian Sekolah Rendah (UPSR), students are assessed on various language skills including vocabulary, grammar, reading comprehension and writing. Under reading comprehension component, students are required to answer ten multiple choice items based on a non-linear text and linear text (Malaysian Education Syndicate, 2008). Therefore, a suitable reading comprehension assessment should be carefully designed and executed in achieving the objective.

For so many years, Bloom's Taxonomy has been a practical basis for assessment (Marzano \& Kendall, 2007) thus helps teachers to match their exam questions with syllabus and learning objectives (Krathwohl, 2002). The Bloom's Taxonomy's cognitive domains are arranged from simple to complex. They include six levels of knowledge, comprehension and application in the Lower Order Thinking Skills (LOTS). Analysis, synthesis and evaluation are placed under the HOTS that ranged from concrete to abstract mental processing abilities. The present study, therefore, was carried out to evaluate the HOTS items utilized in the English reading comprehension questions for Standard 6 in eight different states in the country.

The Malaysian Examination Syndicate (2008) has listed reading comprehension as one of the important components in language teaching and learning. Assessment items under this component are basically constructed based on certain expected learning outcome and comprehension skills listed in the syllabus. The teaching and learning of HOTS require specific methods such as proper instructional materials (Chingos \& Whitehurst, 2012), collaborative learning (Johansson, 2017) and a process of engagement, exploration, explanation, elaboration and evaluation (Mutrofin et al., 2016).

The teaching and learning of this particular language component generally aim to develop students' abilities to understand, analyze and synthesize factual information given in various types of reading materials. This, however, cannot be achieved without proper planning and understanding of the basic concepts among teachers and exam setters. Abdul Rashid and Awang Hashim (2008:374) believe that "critical thinking is a form of western culture and that Asian students are unable to think critically because such practice is alien especially in Asian educational contexts and culture".

According to Vijayaratnam (2012), the country needs 'thinking' students who can incessantly respond to the real-world demands. The main reason for this problem is the insufficient exposure and the scarcity of resources to adequately teach HOTS in Malaysian schools and higher learning institutions (Ravinder Singh, 2013). There is a need for the Malaysian Examination Syndicate to construct various levels of assessment components under HOTS to be included in high-stakes examinations such as UPSR to cater to students' skills and abilities. Failing to do so, students with intermediate or low cognitive level will face difficulties in understanding, let alone answering the items; while the advanced ones will find the items too easy or not challenging at all. In addition, students basically come to class with different background knowledge and past experience and these somehow have shaped and determined their cognitive levels.

Despite many studies that have reported on the use of HOTS in teaching and learning, not much have been done on the English reading comprehension skills and assessments, especially involving the primary education system in Malaysia. Sean and Lee (2011) study, for instance evaluated the HOTS items used in the Malaysian University English Test (MUET). The present 
study, therefore, aims to: (i) evaluate the use of HOTS items in the English reading comprehension papers for Standard 6 in Malaysia and (ii) identify the specific skills demonstrated under HOTS category in English reading comprehension papers in Malaysia.

Reading comprehension items are used to measure readers' skills and ability to understand and interact with various types of reading materials. Comprehension is a creative and multifaceted process that underpins one's grasp of certain language skills. Proficient reading depends on the ability to comprehend information quickly and effortlessly. It is also determined by a student's cognitive development as some students learn through formal instructions whereas others acquired knowledge through early life exposure and experience.

Reading comprehension assessment is the most common type of published assessments (Reading Resources, 2009). The most common reading comprehension assessment involves asking students to understand a text and derive some explicit and detailed information pertaining to its content. Reading comprehension items come in various styles and strategies. For example, instead of explicit items about facts directly presented in the text, students might be asked to answer inferential items about information implied by the text. The items, however, are arranged appropriately according to their level of complexity.

\section{Theoretical framework: Bloom's Taxonomy}

Bloom's Taxonomy was established in 1956 to categorize the complexity of items according to certain cognitive skills and ability. The main purpose of this theory is to provide the right cognitive levels of questioning in the construction of test papers. The taxonomy is made of three parts; cognitive domain, effective domain and psychomotor domain. Bloom et al. (1956) proposed that the most important domain of all three would be the cognitive domain that involves the process of transferring information into knowledge. The present study, therefore, focuses only on the cognitive domain since it is very much related to the reading comprehension skills and assessment.

Cognitive domain involves the process of information as well as the development of thinking skills and abilities. It also includes the recognition of specific evidences and concepts that help develop one's intellectual abilities and skills. Cognitive domain consists of six levels starting from the lowest level that involves the retention of information and the ability to recall knowledge and ends at the highest level of thinking such as critical thinking and the ability to synthesize and evaluate. The first three levels, namely knowledge, comprehension and application are known as the LOTS while analysis, synthesis and evaluation are categorized as HOTS. Higher-order thinking is thinking that operates at the highest levels of cognitive processing.

Bloom's Taxonomy is the most widely accepted categorization of this sort in education and it can be seen as a range of thinking skills starting with the lower knowledge-level thinking to the evaluation-level of thinking. The taxonomy is a set of thinking skills that come in order. As an example, before learner achieves the analysis level, he/she also has to acquire the lower levels of knowledge, comprehension and application. Bloom's taxonomy helps to guide teachers in designing students' activities according to their cognitive abilities (Narayanan, 2015). It helps teachers to contextualize the level of thinking skills involved in each lesson and assessment. Students need to understand and acquire the skills before they are assessed. Through the use of a 
variety of teaching techniques and approaches to encourage LOTS and HOTS, the student will start to implement the application, analysis, synthesis and evaluation of new knowledge.

In the teaching of the English language, the implementation of learning activities based on Bloom's taxonomy is also associated with other aspects such as multiple intelligences, critical thinking, problem solving skills and more recently language integration skills. The categorization and construction of exam items should begin from lower to higher-order thinking skills. This process starts with the knowledge to the comprehension level before reaching the highest level known as evaluation. The arrangement of questions should be made according to their level of difficulty. Most importantly, good exam questions are designed to test and measure students' multiple skills and levels of understanding (Hiu et al., 2006).

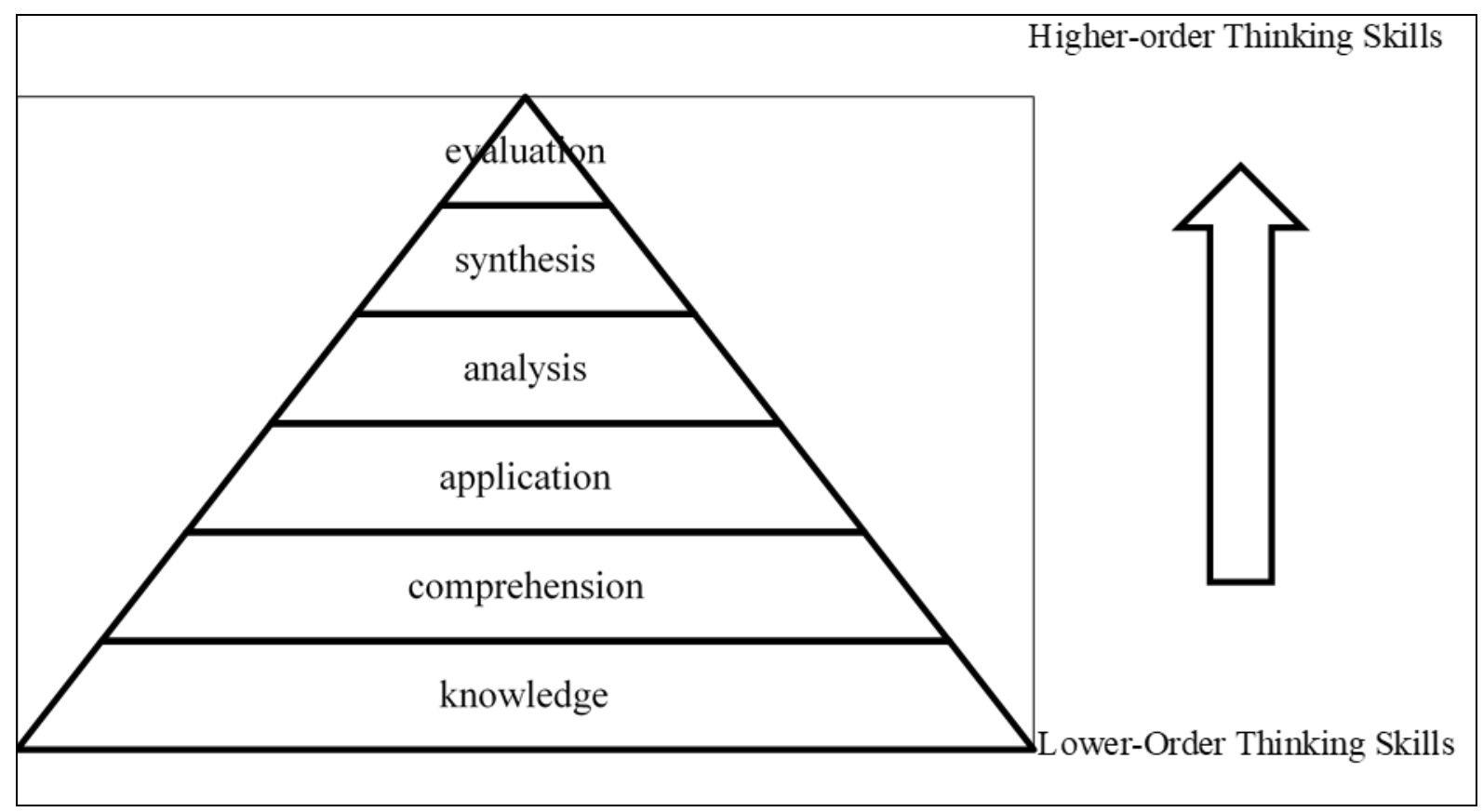

Figure 1. Lower to Higher-order Thinking Skills' levels 
The following table demonstrates some basic keywords that are normally appeared in questions, based on the level of thinking skills:

Table 1. Basic keywords based on the level of thinking skills

\begin{tabular}{|c|c|c|c|c|c|}
\hline Knowledge & Comprehension & Application & Analysis & Synthesis & Evaluation \\
\hline acquire & conclude & apply & analyze & arrange & appraise \\
\hline define & describe & calculate & appraise & assemble & argue \\
\hline know & discuss & demonstrate & categorize & collect & assess \\
\hline identify & draw & dramatize & classify & Combine & choose \\
\hline list & explain & employ & compare & compost & compare \\
\hline memorize & express & exhibit & contrast & construct & conclude \\
\hline name & express & illustrate & criticize & create & consider \\
\hline recall & identify & interpret & debate & derive & criticize \\
\hline recognize & illustrate & operate & deduce & design & decide \\
\hline record & infer & organize & detect & develop & deduce \\
\hline relate & interpret & practice & diagram & document & estimate \\
\hline \multirow[t]{18}{*}{ repeat } & locate & relate & differentiate & formulate & evaluate \\
\hline & recognize & restructure & discover & generalize & infer \\
\hline & report & schedule & discriminate & invent & judge \\
\hline & represent & show & dissect & modify & measure \\
\hline & restate & sketch & distinguish & organize & rate \\
\hline & review & translate & examine & originate & revise \\
\hline & translate & use & experiment & plan & score \\
\hline & & & inquire & predict & select \\
\hline & & & inspect & prepare & validate \\
\hline & & & inventory & produce & value \\
\hline & & & investigate & propose & \\
\hline & & & probe & relate & \\
\hline & & & question & set up & \\
\hline & & & scrutinize & & \\
\hline & & & separate & & \\
\hline & & & solve & & \\
\hline & & & survey & & \\
\hline & & & test & & \\
\hline
\end{tabular}

Source: MESA Communiy College, 2019

Several previous studies have indicated how HOTS can be integrated in reading comprehension lessons and assessments. Luebke and Lorie (2013) for instance, examined reading comprehension specifications involving both lower and higher-order thinking skills, using the LSAT Reading Comprehension Categories. This framework classifies reading comprehension questions (or items) into four categories: (1) Recognition, (2) Understanding and Analysis, (3) Inference, and (4) Application, Luebke and Lorie (2013) revealed that the cognitive level measured in LSAT Reading Comprehension can be useful on a general level, but not effective enough on an individual level.

Ahmed et al. (2013) analyzed selected final exam questions in several high schools in Iran using Blooms's Taxonomy. Their findings indicate that all the exam questions designed for first and second-grade students are at the first three levels of the taxonomy, which are among the 
lowest order of thinking. One of the reasons was the use of multiple choice questions due to teachers' preferences for easy marking schemes and scoring procedures.

Khorsand (2009) analyzed the cognitive level of questions used by a group of Iranian teachers in English reading comprehension tests. Khorsand (2009) found that more than $90 \%$ of the questions are categorized as belonging to the first two levels of the taxonomy. One of the reasons given by Khorsand would be the lack of awareness, knowledge, questioning skills and exposure among teachers as well as exam setters.

\section{Methods}

The present study employed a quantitative approach in order to identify the use of HOTS items in selected English reading comprehension examination for Standard 6 students in Malaysia. Altogether, 80 reading comprehension items were selected from eight English examination papers prepared for students in eight different states in Malaysia; Johor, Kedah, Pahang, Selangor, Kelantan, Terengganu, Kuala Lumpur and Negeri Sembilan. The items were quantitatively analysed using content analysis based on the HOTS aspects listed in Bloom's Taxonomy. Apart from that, the items were also analyzed based on a series of professional evaluations made by four content experts in the country who have been working as English language teachers for more than 15 years and have vast experience in setting up English language examination papers at the national level. The analysis of items is categorized into three parts.

(i) Part 1- the evaluation of items according to LOTS and HOTS listed in Bloom's Taxonomy. These items are reading comprehension- multiple choice questions.

(ii) Part 2- the levels of HOTS in Bloom's Taxonomy. Reading comprehension items were then categorized into the three levels; analysis, synthesis and evaluation.

(iii) Part 3- the subskills under each main skill- analysis, synthesis and evaluation level of HOTS items.

\section{Findings}

Firstly, out of 80 reading comprehension questions involved in the analysis, 64 questions were categorized as the lower-order thinking skill-questions (80\%) and only 16 items (20\%) were categorized as belonging to the higher-order thinking questions. Some samples of reading comprehension items in the examination papers that were evaluated and categorized under LOTS and HOTS are presented in Table 2. 
Table 2. Samples of LOTS and HOTS Reading Comprehension Items in English Examination Papers

\begin{tabular}{ll}
\hline Level & \multicolumn{1}{c}{ Question } \\
\hline LOTS & $\begin{array}{l}\text { What were the strategies used by the } 1964 \text { winner? } \\
\text { A. non-violent }\end{array}$ \\
$\begin{array}{l}\text { understand basic story line of } \\
\text { literal meaning of a text }\end{array}$ & $\begin{array}{l}\text { B. hunger strikes } \\
\text { C. provides food } \\
\text { D. peaceful ways }\end{array}$ \\
HOTS & $\begin{array}{l}\text { The middle man that mentioned in the passage is a_ } \\
\text { A. whole seller } \\
\text { interpret a text on a more } \\
\text { abstract level }\end{array}$ \\
& $\begin{array}{l}\text { B. medium-sized man } \\
\text { C. person who buys and sells things } \\
\text { D. person who knows all the pet shop owners } \\
\text { (Question 38, Pahang) }\end{array}$ \\
\hline
\end{tabular}

The highest number of HOTS items, which were only three items (4\%) were found in exam questions for students in Kedah and Negeri Sembilan whereas exam questions made for students in Selangor, Kelantan, Terengganu and Kuala Lumpur only contain two HOTS items.

Table 3. Frequencies and percentages of LOTS and HOTS Reading Comprehension Items of English Examination Papers based on Bloom's Taxonomy

\begin{tabular}{lcccc}
\hline State & \multicolumn{2}{c}{ LOTS } & \multicolumn{2}{c}{ HOTS } \\
& Frequency $(\mathbf{N})$ & Percentage $(\%)$ & Frequency (N) & Percentage (\%) \\
\hline Johor & 9 & 11.0 & 1 & 1.0 \\
Kedah & 7 & 9.0 & 3 & 4.0 \\
Pahang & 9 & 11.0 & 1 & 1.0 \\
Selangor & 8 & 10.0 & 2 & 2.5 \\
Kelantan & 8 & 10.0 & 2 & 2.5 \\
Terengganu & 8 & 10.0 & 2 & 2.5 \\
Kuala Lumpur & 8 & 10.0 & 2 & 2.5 \\
Negeri Sembilan & 7 & 9.0 & 3 & 4.0 \\
\hline
\end{tabular}

The findings of this study indicate a lack of HOTS items in the English language reading comprehension questions in most states in Malaysia. Al-Btoush (2012) believed that teachers resort to the basic levels of questions due to their lack of confidence in their students' ability to answer critical questions. Assessments that are prepared for students whose mother tongue is not English are normally easier than their expected level of knowledge and understanding due to teachers' low expectation towards students' capability and achievement. 


\section{The implementation of Higher-Order Thinking skills in English Language-Reading} Comprehension Questions in Malaysia

Table 4. Samples of Reading Comprehension Items in HOTS levels

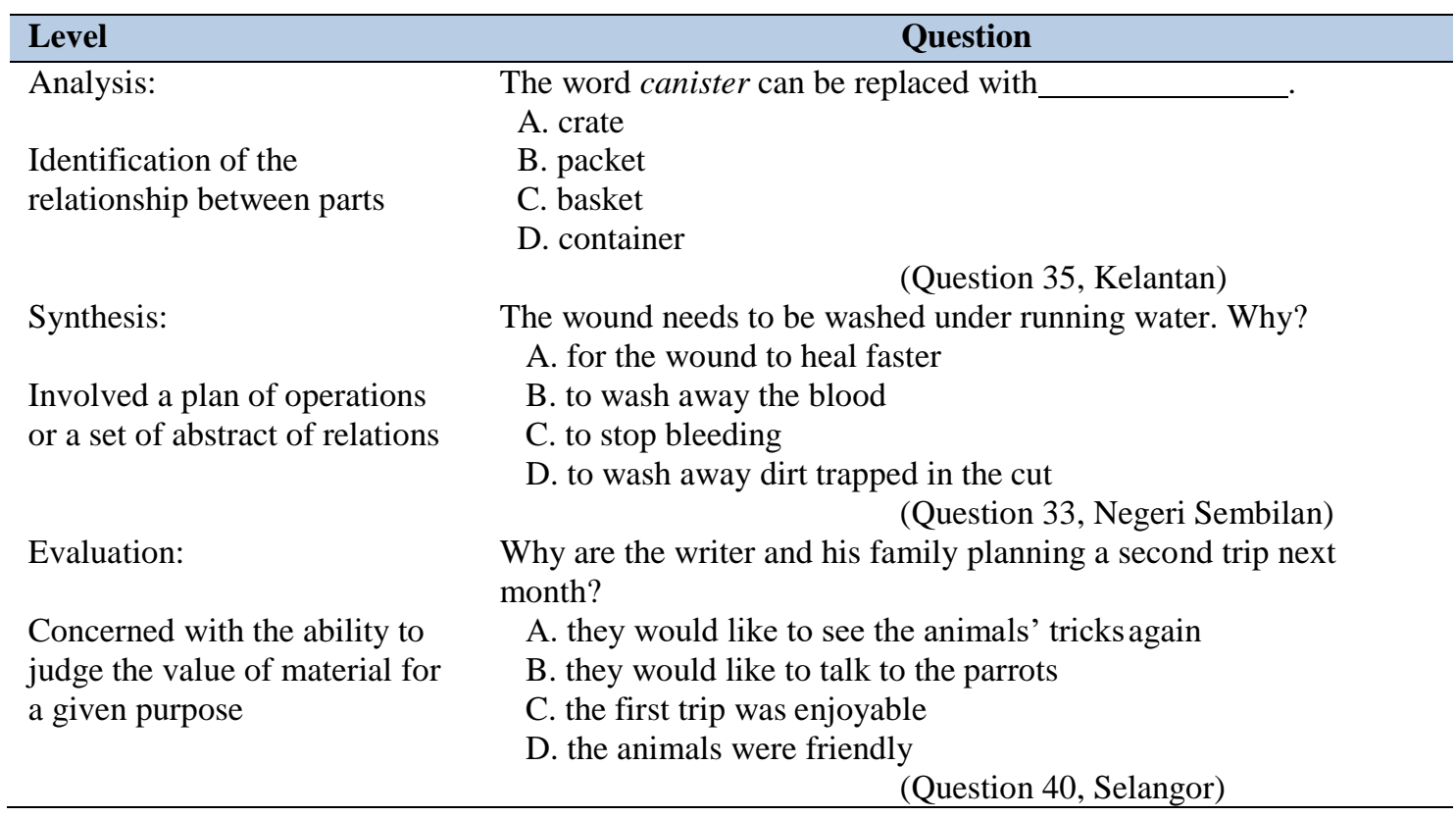

The items were analyzed and categorized as follows:

(i) Nine (56\%) items were categorized as belonging to the knowledge level.

(ii) Only two (13\%) items were categorized as belonging to the analysis level.

(iii) Five (31\%) items were categorized as belonging to the evaluation level.

Our analysis, however, did not find any questions that require students to synthesize and evaluate reading information. These two aspects were not tested in all Standard 6 English reading comprehension exam papers involved in this study. The next section discusses the categorization of subskills under the analysis, synthesis and evaluation levels. The sample of questions and assessed skills are presented in Table 5. 
Table 5. Sample of questions and subskills

\begin{tabular}{|c|c|c|}
\hline Level & Question & Subskill \\
\hline Analysis & $\begin{array}{l}\text { The idiom building castles in the air means } \\
\text { A. remember suddenly } \\
\text { B. following rules } \\
\text { C. daydreaming } \\
\text { D. not brave enough } \\
\text { (Ouestion 35, Kedah) }\end{array}$ & $\begin{array}{l}\text { recognition of } \\
\text { hidden meanings }\end{array}$ \\
\hline Synthesis & $\begin{array}{l}\text { The wound needs to be washed under running water. Why? } \\
\text { A. for the wound to heal faster } \\
\text { B. to wash away the blood } \\
\text { C. to stop bleeding } \\
\text { D. to wash away dirt trapped in the cut } \\
\text { (Question 33, Negeri Sembilan) }\end{array}$ & draw conclusion \\
\hline Evaluation & $\begin{array}{l}\text { The purpose of the treatment is to reduce the } \\
\text { A. pain } \\
\text { B. size of the cut } \\
\text { C. risk of infection } \\
\text { D. swelling of the wound }\end{array}$ & $\begin{array}{l}\text { compare and } \\
\text { discriminate between } \\
\text { ideas }\end{array}$ \\
\hline
\end{tabular}

The above items are samples of reading comprehension questions categorized under certain subskills of HOTS. The question that seeks for an interpretation of idiom 'castles in the air' for instance, requires students to use their existing knowledge and understand English idioms based on certain contexts. Answers to questions about idioms and idiomatic expressions require an analysis thinking skill to recognize hidden meanings and contextualizing it based on readers' background knowledge. The above question, however, requires analytical thinking at a very superficial level. Open ended questions that require students to summarize or explain idioms would indicate a better application of knowledge and skills because instead of having students to simply remember (level one of Bloom's Taxonomy) the meaning of idioms, open ended question allows them to explain the phrases in their own words thus evaluating and contextualizing it to the given situation or phenomenon in the text (level five of Bloom's Taxonomy). Questions under this category (analysis) however, only appeared nine times in the entire data involved in this study.

We only found two items that require synthesis thinking skill, out of eight samples of questions (from eight different states in Malaysia). One of the items was given as sample in Table 4. This question required students to know and understand the process of cleaning a wound and draw a conclusion by identifying the possible reason behind the procedure. The next question (derived from the same text) required students to identify the purpose of the woundhealing treatment. This question was categorized as 'evaluation' since it tests student's ability to compare several information given in the text, assess and choose the best option. Evaluation questions, however, appeared only five times in the entire database involved in this study. Table 6 and 7 indicate the overall number of items that are categorized under HOTS. 
Table 6. Number of questions categorized as belonging to HOTS

\begin{tabular}{lcc}
\hline Levels of HOTS & Frequency $(\mathbf{N})$ & Percentage $(\%)$ \\
\hline Analysis & 9 & 56 \\
Synthesis & 2 & 13 \\
Evaluation & 5 & 31 \\
\hline
\end{tabular}

Table 7. Number of questions belonging to the subskills of analysis, synthesis and evaluation levels

\begin{tabular}{llcc}
\hline Level & \multicolumn{1}{c}{ Subskills } & Frequency $(\mathbf{F})$ & Percentage (\%) \\
\hline analysis & seeing patterns organization of parts & 0 & 0.0 \\
& recognition of hidden meanings & 2 & 12.0 \\
& identification of components & 7 & 44.0 \\
& & 0 & 0.0 \\
synthesis & use old ideas to create new ones generalized & 0 & 0.0 \\
& from given facts & 1 & 6.5 \\
& relate knowledge from several areas predict, & 0 & 0.0 \\
& draw conclusion & 1 & 6.5 \\
evaluation & compare and discriminate between ideas & 1 & 6.5 \\
& assess values of theories, presentations make & 0 & 0.0 \\
& choices based on reasoned argument verify & 4 & 24.5 \\
& value of evidence & 0 & 0.0 \\
& recognize subjectivity & & \\
\hline
\end{tabular}

\section{Discussion}

Firstly, the findings revealed an insufficient amount of HOTS questions in the English reading comprehension assessment for Standard 6 students in Malaysia. Out of 80 items involved in the analysis, only 16 items fall under the categorization of higher order thinking skill-questions. Exam setters need to take a serious consideration in having all the necessary skills when preparing examination papers in order to have a comprehensive and balanced assessment system. It is important for schools to have a teaching and learning model that facilitates students' higher order thinking skills in order to make them understand their own cognitive ability in making critical judgments and decisions; with assessment being part of the model. This is deemed important in enhancing individuals' learning performance and cognitive development (Donald, 2002; Perkins et al., 1993). The right structure and components of assessment are also important in identifying the effectiveness of a teaching and learning model.

Next, as one of the most important agents in the educational system who have direct access to students and responsible in organizing their learning experiences, teachers need to understand, practice and utilize HOTS (Barak \& Dori, 2009) in order to deliver learning skills effectively. Azian et al. (2017) believed that Malaysian teachers need to get out of their comfort zone and shift from conventional to a modern way of developing content knowledge in order to promote and enhance critical thinking skills among students. This is in line with the Malaysia Education Blueprint, which states that the new focus of the Malaysian education system is not just on "the importance of knowledge, but also on the developing higher-order thinking skills" (2012:25)

With only 16 questions from the total of 80 questions taken from eight sets of English papers distributed to level 6 students (the highest level of the Malaysian-primary school system) in eight different states in Malaysia, the findings revealed a minimum exposure of HOTS at this level of 
English language assessment. Lack of teaching and learning preparation might contribute to the failure of HOTS implementation in the classroom (Azian et al., 2017). Al-Btoush (2012) believes that teachers who teach English as a second or foreign language normally want to make assessment less complicated for their students and resort to having lower order thinking skillquestions that will not require a lot of analysis, discussion and interpretation.

As the findings also did not indicate any question that tested on important subskills such as reasoning arguments, verifying the value of evidence and recognizing subjectivity, it is believed that these skills are not highly emphasized in teaching and learning thus testing them was not seen as important. Leaman and Flanagan (2013) believed that having impromptu activities such as role play followed by reflection-in-action will encourage various levels of critical thinking skills as these activities involve specific thinking activities among students such as analyzing, reasoning and synthesizing information before conducting discussions about their role play experience. Other teaching and learning activities that promote reasoning and verifying evidence would be problem-based learning and collaborative activities (Erduran \& Msimanga, 2014) as well as prompting and questioning (King et al., 2012; Manzo \& Manzo, 2013).

It is important for language teachers to integrate HOTS in their teaching and learning practices in order to facilitate critical thinking process among students. Students will be able to understand and use language across variety of contexts and relate learning with their own language experience and this makes the learning more fun and effective. Porath (2014) believed that discussions pertaining to reading texts will be more effective when teachers "involve the student in creating a shared and dynamic understanding of the student's reading interests and processes" (Porath, 2014: 627). Critical discussion that involves thinking out loud helps students to improve cognitive ability and enhance their performance on difficult tasks (Lupyan \& Swingley, 2012). Involving students in conversations about reading texts not only facilitate their learning but also help teachers to measure students' progress in specific reading skills and thinking abilities (Porath, 2014).

Teachers play an important role in fostering the strategies and skills necessary for effective reading comprehension. Furthermore, the Malaysian Examination Board has also emphasized on having more questions that test students' HOTS in future national examinations thus integrating these skills and their subskills in language lessons are deemed important for students to succeed in their exams. Given the importance of reading comprehension as part of students' language learning assessment, it is vital for teachers to also understand the types of questions and prompts that should be provided to facilitate students' comprehension in reading using various types of texts and materials. Through this activity, teachers will be able to produce high reasoning abilities among students that will help them cope with other content subjects that require HOTS.

\section{Conclusion}

The findings of the present study have direct implication on teaching and learning practices in Malaysia. Firstly, the teaching and learning of HOTS in Malaysian primary schools should be improved, especially when questions in national exams such as UPSR and PT3 are designed to test students' ability in using these skills. This was mentioned in the Malaysian Education Blueprint (2013-2025) that stated the following: 
By 2016, higher-order thinking questions will comprise at least $40 \%$ of the questions in UPSR and 50\% in SPM. This change in examination design means the teachers will focus less on predicting what topics and questions will come out and drilling for content recall. Instead, students will be trained to think critically and to apply their knowledge in different settings. Similarly, school-based assessments will also shift their focus to testing for higher-order thinking skills.

This transformation in testing and evaluation design means that teachers will have to put less emphasis on the topics that will come out in the exam and focus more on helping students to demonstrate their understanding of key concepts and complex ideas. Not only that, to make sure that all students master the English language, the Ministry of Education will also make it compulsory for them to pass the SPM English paper in order to get the certificate. However, the new policy may not be as good as it sounds if sufficient training and preparation are not provided to teachers; the change agents who are directly responsible in the process of teaching and learning in schools. The question is whether teachers are fully prepared and most importantly, have received a sufficient amount of training before the implementation of such policy. It is very important for teachers to receive effective training programs in order to succeed in doing their job. Previous studies found that the most crucial factor contributing to a student's success in education is the quality of teaching (Mizwell, 2010) and this is achieved through comprehensive training activities and workshops.

Based on the limited number of higher-order thinking questions given in almost all reading comprehension papers observed in this study, the findings implied a limited exposure of this particular aspect among language teachers in Malaysian schools. According to Azian et al. (2017), teachers in Malaysia are basically aware of the need to include HOTS in their teaching and learning activities, but are not able to do so due to their uncertainty of how to go about it.

Most of them were uncertain on how to plan, implement and assess HOTS in the classrooms, for example, in terms of developing individual student's potential with HOTS and evaluating students' HOTS improvement. In fact, based on their self-reflection on HOTS teaching practices, it is evident that the L2 teachers did not routinely emphasize on HOTS during lessons. (Azian et al., 2017: 71).

Johnson (1991) and Riley (1978) emphasized on the effective teacher training as a fundamental aspect of language testing and evaluation practices. Teachers should be encouraged to attend seminars and specific courses designed to enhance their understanding and ability to teach and assess HOTS in a systematic manner.

Next, the current innovation in education has integrated various technology-based teaching and learning approaches that are beneficial in many different aspects of learning. It is not possible for teachers to measure every student's ability, thinking skills, and performance using the same traditional approaches available in old textbooks and teaching materials. With the increasing number of new tools and technologies, teachers should learn and benefit from these new teaching instructions led by technology to develop and enhance students' HOTS and abilities in their classrooms. Traditional teaching approaches can be integrated with new teaching practices, enabling teachers and students to become better equipped for the technologicallyoriented world around us. Not only teachers and educators at all levels of educational institutions need to familiarize and update themselves with the current needs and changes, it is also 
important for them to observe and utilize as many innovative methods as possible. One current study found that ESL teachers encounter various challenges in facilitating the learning process with the integration of ICT as a supplementary tool in promoting higher-order thinking skills (Ganapathy et al., 2017). Future research could look into some possible ways of enhancing HOTS in language classroom using technology-based teaching and learning methods.

It is hoped that the present study serves as a starting point for teachers to evaluate and improve their teaching strategies in enhancing HOTS in their students. Higher-order thinking is identified as one of the main $21^{\text {st }}$ century components as it takes thinking to a whole new level. It is important for our students to be able to use strategic and complex ways of thinking in order to become great future leaders and thinkers.

\section{References}

Abdul Rashid, Rosyati, Awang Hashim, \& Rosna (2008). The relationship between critical thinking and language proficiency of Malaysian undergraduates. In EDU-COM International Conference Conferences, Symposia and Campus Events Proceedings, November 2008, Edith Cowan University, Perth Western Australia.

Ahmed, A., Nisa, A., \& Zarif, T. (2013). Table of specification development and usage: An overview. Interdisciplinary Journal of Contemporary Research Business, 4(12), 354-361.

Al-Btoush, O.A. (2012). An analysis of the question in Jordanian Secondary Stage English Language Textbook. Mu'tah University, Jordan.

Azian Abdul Aziz, Fauziah Ismail, Noor Mala Ibrahim \& Norhanim Abdul Samat. (2017). Investigating the implementation of Higher-order Thinking skills in Malaysian classrooms: Insights from L2 teaching practices. Sains Humanika, 9[4-2(2017)], 65-73.

Barak, M. \& Dori, Y.J. (2009). Enhancing Higher-order Skills among in-service Science teachers via embedded assessment. Journal Science Teacher Education, 20, 459-474.

Bloom, B.S., Engelhart, M.D., \& Furst, E.J. (1956). Taxonomy of educational objectives: Handbook I. London, Longmans Green \& Co. Ltd.

Chingos, M., \& Whitehurst, G.J. (2012). Choosing blindly: Instructional materials, teacher effectiveness, and the common core. Retrieved from http://eric.ed.gov

Donald, J.G. (2002). Learning to think: Disciplinary perspectives. San Francisco, C.A., JosseyBass.

Erduran S. \& Msimanga A. (2014). Science curriculum reform in South Africa: Lessons for professional development from research on argumentation in Science Education. Education as Change, 18(1), 33-46.

Ganapathy, M., Singh, M.K.M., Kaur, S., \& Kit, L.W. (2017). Promoting Higher-order Thinking skills via teaching practices. 3L: Language, Linguistics, Literature. 23(1), 75-85.

Hiu, L.P., Ngo, K.L., \& Jbyamahla, V. (2006). An analysis of the level of thought processes of the RCQs in the Malaysian University English Test (MUET), paper 3, reading comprehension, May 2004 and the Uitm Jengka students' performance in this MUET exam paper. Research Report. Retrieved from: The Institute of Research Development and Commercialization. Universiti Teknologi Mara. 
Johansson, E. (2017). Assessing for Higher-Order Thinking skills: An international study of university teachers' perception of developing e-assessment that fosters higher level outcomes.

Johnson, C.S., \& Evans, A.D. (1991). Improving teacher questioning: A study of a training program. Retrieved from https://www.eric.edu.gov.com.

Khorsand, N. (2009). Cognitive levels of questions used by Iranian EFL teachers in advanced reading comprehension tests. Retrieved from http://eric.ed.gov.

King, F.J., Goodson, L., \& Rohani, F. (2012). Higher-order Thinking skills: Definitions, Teaching strategies, assessment. Retrieved from http://www.cala.fsu.edu.

Krathwohl, D. (2002). A revision of Bloom's Taxonomy: An overview. Theory into Practice, 41(4), 212-218.

Leaman, L., \& Flanagan, T. (2013). Authentic role-playing as situated learning: Reframing teacher education methodology for Higher-order Thinking. Studying Teacher Education, 9 (1), 45-61.

Luebke, S., \& Lorie, J. (2013). Use of Bloom's Taxonomy in developing reading comprehension specifications. Journal of Applied Testing Technology, 14, 1-27

Lupyan, G., \& Swingley, D. (2012). Self-directed speech affects visual search performance. The Quarterly Journal of Experimental Psychology, O(00), 1-18.

Malaysian Education Syndicate. (2008). Find a publication education system: Malaysia. Retrieved from https://www.epnuffic.nl.

Manzo, U., \& Manzo, A.V. (2013). The informal reading-thinking inventory: Twenty-firstcentury assessment formats for discovering reading and writing needs and strengths. Reading \& Writing Quarterly, 29(3), 231-251.

Marzano, R., \& Kendall, J. (2007). The new Taxonomy of Educational Objectives. (2 ${ }^{\text {nd }}$ ed.). Thousand Oaks, C.A., Corwin Press.

MESA Community College. 2019. Blooms higher level verbs. Retrieved from https://www.mesacc.edu.

Ministry of Education. (2012). Malaysia Education Blueprint 2013-2025: Preliminary Report. Retrieved from http://www.moe.gov.my.

Mizwell, H. (2010). Why professional development matters: Learning forward. Retrieved from https://learningforward.org.

Mutrofin, L., Nur, M., \& Yuanita, L. (2016). Developing teaching materials using 5E model of instruction to increase students' Higher-order Thinking skills. JPPS: Jurnal Penelitian Pendidikan Sains, 5(2), 962-967.

Narayanan, S., \& Adithan, M. (2015). Analysis of question papers in Engineering courses with respect to HOTS (Higher-order Thinking skills). American Journal of Engineering Education, 6(1), 1-10

Perkins, D., Jay, E., \& Tishman, S. (1993). New conceptions of thinking: From ontology to education. Educational Psychologist, 28(1), 67-85.

Porath, S. (2014). Talk less, listen more: Conferring in the reader's workshop. The Reading Teacher, 67(8), 627-635

Ravinder, S. (2013). Examination board lacks HOTS. Retrieved from http://www.freemalaysiatoday.com

Riley, J.P. (1978). Effects of studying a question classification system on the cognitive level of preservice teachers' questions. Science Education, 62(3), 333-338. 
Sean, A.H.L., \& Lee, E.W. (2011). Involvement of higher order thinking skills within a preparatory course for the Malaysian University English Test. The English Teacher. 11, 95112.

Serafini, F. (2010). Classroom reading assessments: More efficient ways to view and evaluate your readers. Portsmouth, NH, Heinemann.

Vijayaratnam, P. (2012). Developing Higher-order Thinking skills and team commitment via group problem solving: A bridge to the real world. $8^{\text {th }}$ International Language for Specific Purposes (LSP) Seminar: Aligning Theoretical Knowledge with Professional Practice. 